\title{
Equivalent Circuit Model for MEMS Vibrational Energy Harvester Compatible with Sinusoidal and Nonsinusoidal Vibrations
}

\author{
Hiroaki Honma, Yukiya Tohyama, Sho Ikeno, and Hiroshi Toshiyoshi \\ Institute of Industrial Science, The University of Tokyo, 4-6-1 Komaba, Meguro-ku, Tokyo 153-8505, Japan
}

(Received February 3, 2020; accepted March 2, 2020)

Keywords: vibrational energy harvester, LTspice, electret, sinusoidal vibration, nonsinusoidal vibration

We build an equivalent Simulation Program with Integrated Circuit Emphasis (SPICE) model for a vibrational energy harvester comprising comb electrodes coated with an electret film that is used to convert the vibrational kinetic energy into electrical output power by electrostatic induction. In the assembled module, sinusoidal and nonsinusoidal vibrations are imported into the nonlinear current sources as an inertial force, and the power-generating performances are simulated. The nonsinusoidal waves observed in an actual environment (highway duct) are used as an input sample. By quantitatively comparing the simulation and experimental results, we verify the applicability of the equivalent module for various vibrations. When the device is excited by sinusoidal vibration, the maximum output power is calculated to be $71 \mu \mathrm{W}$ at $0.044 \mathrm{G}\left(1 \mathrm{G}=9.8 \mathrm{~m} / \mathrm{s}^{2}\right)$, which is close to the experimental result of the actual device, $68 \mu \mathrm{W}$ at $0.045 \mathrm{G}$. Furthermore, when importing a nonsinusoidal vibration, the two timings at the highest generating peak are obtained in accordance with the moment of resonance, and the amplitudes are experimentally and analytically obtained to be 0.80 and $0.63 \mathrm{~V}$, respectively.

\section{Introduction}

Interest in Internet of Things (IoT) has been growing since it is expected to work as a maintenance- and operation-assisting apparatus in social infrastructures. Today's widely used sensor nodes commonly have the problems of the need for battery replacement. Hence, the integration of sensor nodes with the autonomous power sources such as environmental energy harvesters could be a solution to extending their lifetime. ${ }^{(1-6)}$ Ambient vibrations are highly promising as power source for wireless sensor nodes. However, harvesting from the environmental vibrations is difficult because they are usually distributed in a frequency range of $200 \mathrm{~Hz}$ or lower and in an acceleration range of $0.1 \mathrm{G}\left(1 \mathrm{G}=9.8 \mathrm{~m} / \mathrm{s}^{2}\right)$ or less. Recently, micro-electromechanical systems (MEMS)-based vibrational energy harvesters have been drawing intense research interest owing to their resonance function to amplify vibrations in the range of small accelerations. ${ }^{(7-23)}$ The vibrational energy harvesters are grouped into three types, namely, piezoelectric, electromagnetic, and electrostatic, depending on the mechanism of inducing electrical charges. In particular, an electret-based energy harvester can effectively

*Corresponding author: e-mail: honma-hh@iis.u-tokyo.ac.jp

https://doi.org/10.18494/SAM.2020.2821 
harvest ambient vibrational energy owing to the flexibility of the MEMS design that allows it to adapt to the various frequency ranges.

The power-generating efficiency of the energy harvesters based on the MEMS technologies can increase when the frequency of environmental vibrations is equal to its resonant frequency; however, when the resonance is off, the performance of power generation is severely degraded. For this reason, for conventional vibrational energy harvesters, the vibration information relevant to the placement of the sensor node must be analyzed beforehand and must be taken into account in the design phase. In addition, we must be aware of the difference between the sinusoidal and nonsinusoidal vibrations. Regardless of the pattern of the environmental vibration, a reliable simulation method must be developed to foresee the behaviors of energy harvesters.

Because a general vibrational energy harvester receives kinetic energy and delivers electrical energy to the subsequent system, a Simulation Program with Integrated Circuit Emphasis (SPICE) simulation is a helpful multiphysics analysis for handling the physics in two different domains. Subcircuit models for an electrostatic microactuator and a piezoelectric microactuator have been reported and can also be used to simulate the performance of the energy-harvesting systems. ${ }^{(24-26)}$ SPICE simulation results for the PZT-based energy harvester have been presented in a previous report. ${ }^{(27)}$ Furthermore, the equivalent circuit model of the electrostatic energy harvester has been presented, and the simulation results are in good agreement with the measurement results obtained from the developed energy harvesters. ${ }^{(28,29)}$ Subcircuit models of the electrostatic energy harvester based on electrets have also been developed, and the speculated output performances have been reported. ${ }^{(30)}$ In this case, the kinetic power input to a harvesting system is modelled using a constant-voltage source for a SPICE simulation. However, only sinusoidal waveforms have been used, and accordingly, the output performances when using nonsinusoidal vibration still have not been analyzed in subcircuit models. Moreover, the relationship between the output power and input kinetic energy still has not been elucidated and neither has the applicability of subcircuit models under various environments.

In this paper, SPICE models for an energy harvester composed of a comb electrode covered with an electret film are designed. By using such SPICE models, the harvesting system and actuations in the case of sinusoidal and nonsinusoidal vibrations are determined. Moreover, by comparing the simulated value and the experimental value, we verify the applicability of the subcircuit models for various vibrations.

\section{Electret-based MEMS Energy Harvester}

\subsection{Actual device}

Figure 1 shows a photograph and a scanning electron microscopy (SEM) image of the developed vibrational energy harvester with a comb electrode coated with an electret film. Details of the device structures and fabrication techniques have been reported elsewhere. ${ }^{(31)}$ The device has symmetric comb-electrode structures that effectively cancel the electrostatic constraint force. A total of 900 pairs of comb fingers with a gap length of $14 \mu \mathrm{m}$, a tip length of 


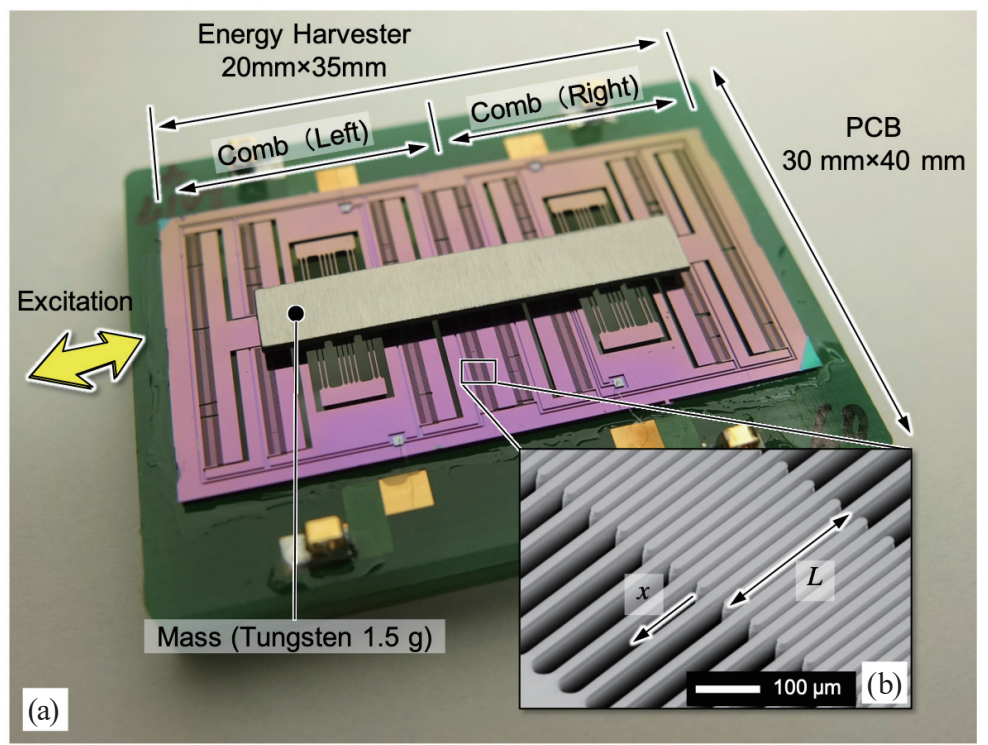

Fig. 1. (Color online) Photograph of developed three-port harvester device and a close-up SEM view of the comb electrodes.

$700 \mu \mathrm{m}$, and a height of $100 \mu \mathrm{m}$ have been made. The comb electrode is designed to handle an electrode stroke of $\pm 350 \mu \mathrm{m}$ and is coated with electrets charged at about $-250 \mathrm{~V}$ with respect to the moving shuttle. The electret film consists of a thin silicon oxide film including potassium ions. The fabrication process of the electret film has been reported elsewhere. ${ }^{(32)}$ Supporting hinges are designed to have a spring constant of $925 \mathrm{~N} / \mathrm{m}$. Owing to the added mass made of tungsten of $1.5 \mathrm{~g}$ on the movable electrode, the resonant frequency is experimentally observed at $125 \mathrm{~Hz}$. Moreover, mechanical damping of the developed harvester was calculated to be 0.0015 from the experimental result of the quality factor.

\subsection{Design of subcircuit model of electret comb structure}

A module for a fully developed energy harvester, that is, a subcircuit model of a comb electrode coated with an electret film, is designed and prepared in this work. This subcircuit model is used to represent the electrostatic induction current from the electret, as well as the electrostatic force acting on the comb electrodes. Figure 2 shows the schematic structure of the comb electrode with an electret that is coated on the side of the comb finger. In this figure, the top electrode is movable, and the bottom is fixed. Each comb pair is described by a model with length $T_{t}$, height $H$, and air gap length $g$. The movable electrode is already overlapped with the fixed electrode by the length $L$, and therefore, the total overlap length of electrodes becomes $L+x$ when the movable electrode is further displaced by $x$. As illustrated in Fig. 2, the air and electret films of this model have the relative dielectric constants $\varepsilon_{1}$ and $\varepsilon_{2}$, respectively. The fixed charge is located from the film surface to the depth $R$ in the electret layer. The detailed 


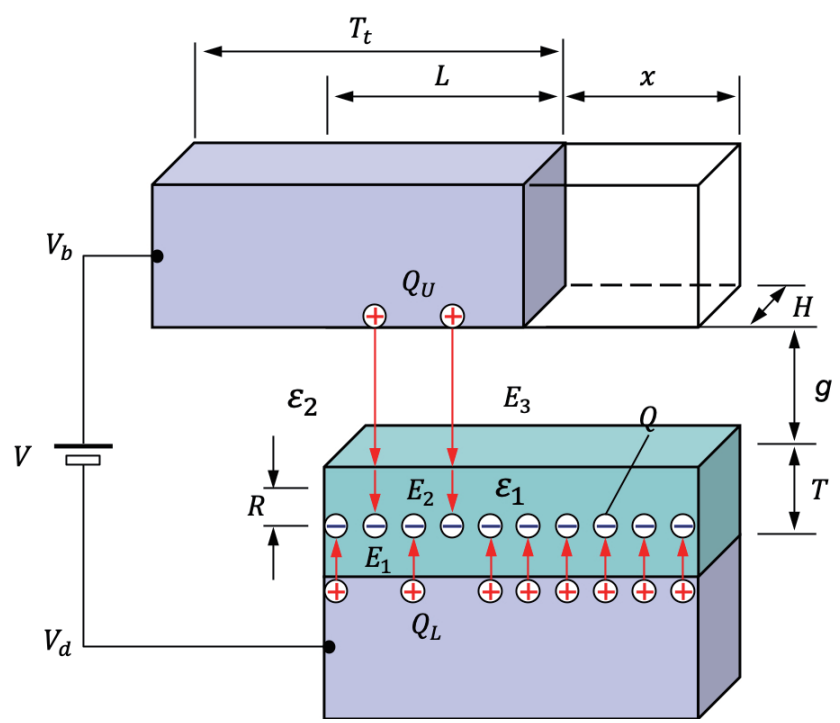

Fig. 2. (Color online) Analytical model of comb electrodes with electret charges.

study of the analytical model has been reported elsewhere, ${ }^{(30)}$ but we discuss the procedure of modeling here again since its final implementation as a SPICE module is different.

Applying Gauss's law to the electrical field $E_{1}$ in the lower side of the silicon oxide, $E_{2}$ in the upper side, and $E_{3}$ in the air gap, we write

$$
\begin{aligned}
& -\varepsilon_{0} \cdot \varepsilon_{1} \cdot E_{1}+\varepsilon_{0} \cdot \varepsilon_{1} \cdot E_{2}=\sigma \\
& -\varepsilon_{0} \cdot \varepsilon_{1} \cdot E_{2}+\varepsilon_{0} \cdot \varepsilon_{2} \cdot E_{3}=0
\end{aligned}
$$

where $\varepsilon_{0}$ is the dielectric constant of vacuum. These electrical fields build up a voltage difference equal to the applied DC voltage $V$, and thus,

$$
E_{1} \cdot(T-R)+E_{2} \cdot R+E_{3} \cdot g=-V
$$

By simultaneously solving these three equations, one obtains the electric fields

$$
\left(\begin{array}{c}
E_{1} \\
E_{2} \\
E_{3}
\end{array}\right)=\left[\begin{array}{c}
\frac{\sigma g \varepsilon_{1}+\sigma T \varepsilon_{2}+\sigma R \varepsilon_{2}{ }^{2}-\sigma T \varepsilon_{2}{ }^{2}+V \varepsilon_{0} \varepsilon_{1} \varepsilon_{2}{ }^{2}}{g \varepsilon_{0} \varepsilon_{2}{ }^{2}+T \varepsilon_{0} \varepsilon_{2} \varepsilon_{1}} \\
V+\frac{\sigma(R-T)}{\varepsilon_{0} \varepsilon_{1}} \\
-\frac{g \varepsilon_{1}}{\varepsilon_{2}} \\
\frac{\sigma R \varepsilon_{2}-\sigma T \varepsilon_{2}+V \varepsilon_{0} \varepsilon_{1} \varepsilon_{2}}{g \varepsilon_{0} \varepsilon_{1}+T \varepsilon_{0} \varepsilon_{2}}
\end{array}\right] .
$$


As a result, the total electrostatic energy stored in one unit of the comb tips is

$$
\begin{aligned}
U(x)= & \frac{1}{2} \varepsilon_{0} \varepsilon_{1} E_{1}^{2}(T-R)(L+x) H+\frac{1}{2} \varepsilon_{0} \varepsilon_{1} E_{2}^{2} R(L+x) H \\
& +\frac{1}{2} \varepsilon_{0} \varepsilon_{2} E_{3}^{2} g(L+x) H+\frac{1}{2} \varepsilon_{0} \varepsilon_{1}\left(\frac{\sigma}{\varepsilon_{0} \varepsilon_{1}}\right)^{2}(T-R)\left(T_{t}-L-x\right) H .
\end{aligned}
$$

For virtual displacement $\Delta x$, the total energy will increase by $\Delta U$, as defined by

$$
\Delta U=U(x+\Delta x)-U(x) .
$$

At the same time, the upper electrode will gain additional charges $\Delta Q_{U}$ as

$$
\Delta Q_{U}=-\varepsilon_{0} \varepsilon_{2} U(\Delta x) E_{3} .
$$

Considering the conservation of energy, the sum of the increment of the electrostatic energy and the mechanical work done by the electrostatic force is equalized by the work done by the external voltage $V$ that transferred the charge $\Delta Q$ against the potential difference as

$$
\Delta U+F \cdot \Delta x=V \cdot \Delta Q_{U},
$$

where

$$
V \cdot \Delta Q_{U}=V \cdot \frac{H(\Delta x) \varepsilon_{0} \varepsilon_{2}\left(\sigma R \varepsilon_{2}-\sigma T \varepsilon_{2}+V \varepsilon_{0} \varepsilon_{1} \varepsilon_{2}\right)}{g \varepsilon_{0} \varepsilon_{1}+T \varepsilon_{0} \varepsilon_{2}}
$$

uses the expressions for the electrical fields and derives the electrostatic force as

$$
F=-\frac{H \varepsilon_{2}^{2}\left(\sigma R-\sigma T+V \varepsilon_{0} \varepsilon_{1}\right)^{2}\left(R-R \varepsilon_{2}^{2}+T \varepsilon_{2}^{2}-2 g \varepsilon_{1}-2 T \varepsilon_{2}+g \varepsilon_{1} \varepsilon_{2}\right)}{2 \varepsilon_{0} \varepsilon_{1}\left(g \varepsilon_{1}+T \varepsilon_{2}\right)^{2}}
$$

In this work, we define the electret potential by using the electret density as

$$
\sigma=-\frac{V_{e} \varepsilon_{0} \varepsilon_{1}}{R-T}
$$

The differential voltage $V$ between the comb electrodes is written as $V=V_{b}-V_{d}$, where $V_{b}$ and $V_{d}$ are the potentials of the upper and lower electrodes, respectively. By using these new parameters, the electrostatic force $F$ is rewritten as 


$$
F=-\frac{H \varepsilon_{0} \varepsilon_{1} \varepsilon_{2}^{2}\left(V_{b}-V_{d}-V_{e}\right)^{2}\left(R-R \varepsilon_{2}^{2}+T \varepsilon_{2}^{2}-2 g \varepsilon_{1}-2 T \varepsilon_{2}+g \varepsilon_{1} \varepsilon_{2}\right)}{2\left(g \varepsilon_{1}+T \varepsilon_{2}\right)^{2}} .
$$

Because each comb electrode has two sides to generate the electrostatic force and that the total number of the comb pair in the device is $N$, the net electrostatic force is $F \times 2 N$. The physics model expressed in Eq. (11) is interpreted in the SPICE as

$$
\begin{aligned}
\mathrm{F}_{\mathrm{SPICE}}= & -2 * \mathrm{~V}(\mathrm{~N}) *((\mathrm{~V}(\mathrm{H}) * \mathrm{~V}(\mathrm{ep}) * \mathrm{~V}(\mathrm{ep} 1) * \mathrm{~V}(\mathrm{ep} 2) * * 2 *(\mathrm{~V}(\mathrm{Vb})-\mathrm{V}(\mathrm{Vd})-\mathrm{V}(\mathrm{Ve})) \\
& * * 2 *(\mathrm{~V}(\mathrm{R})-\mathrm{V}(\mathrm{R}) * \mathrm{~V}(\mathrm{ep} 2) * * 2+\mathrm{V}(\mathrm{T}) * \mathrm{~V}(\mathrm{ep} 2) * * 2-2 * \mathrm{~V}(\mathrm{~g}) * \mathrm{~V}(\mathrm{ep} 1) \\
& -2 *(\mathrm{~T}) *(\mathrm{ep} 2)+\mathrm{V}(\mathrm{g}) *(\mathrm{ep} 1) *(\mathrm{ep} 2))) /(2 *(\mathrm{~V}(\mathrm{~g}) *(\mathrm{ep} 1)+\mathrm{V}(\mathrm{T}) *(\text { ep2 })) * * 2)),
\end{aligned}
$$

where $\mathrm{V}(\mathrm{x})$ is a reserved function of SPICE that recognizes the argument $\mathrm{x}$ as voltage and extracts the value as a unitless number. The parameters used in the model are listed in Table 1.

At the same time, the induction current is determined as the amount of charge change per unit time:

$$
I=\frac{d Q_{U}}{d t}=\frac{d}{d t}\left\{\frac{-2 N \varepsilon_{0} \varepsilon_{1} \varepsilon_{2}^{2} H\left(V_{b}-V_{d}-V_{e}\right)(L+x)}{g \varepsilon_{1}+T \varepsilon_{2}}\right\} .
$$

In a similar manner to $F_{S P I C E}$, the current is translated into the SPICE expression as

$$
\begin{aligned}
\mathrm{I}_{\mathrm{SPICE}}= & \operatorname{ddt}[-2 * \mathrm{~V}(\mathrm{~N}) * \mathrm{~V}(\mathrm{H}) * \mathrm{~V}(\mathrm{ep}) * \mathrm{~V}(\mathrm{ep} 1) * \mathrm{~V}(\mathrm{ep} 2) \\
& * * 2 *(\mathrm{~V}(\mathrm{Vb})-\mathrm{V}(\mathrm{Vd})-\mathrm{V}(\mathrm{Ve})) *(\mathrm{~V}(\mathrm{j})+\mathrm{V}(\mathrm{x})) /(\mathrm{V}(\mathrm{g}) * \mathrm{~V}(\mathrm{ep} 1)+\mathrm{V}(\mathrm{T}) * \mathrm{~V}(\mathrm{ep} 2))]
\end{aligned}
$$

where the function $\operatorname{ddt}(\mathrm{x})$ is another reserved function of SPICE to perform the temporal differentiation of $\mathrm{x}$. Refer to Ref. 30 for the definition of other parameters.

Table 1

Design parameters and initial conditions for vibrational energy harvester.

\begin{tabular}{lcc}
\hline Parameter & Symbol & Value \\
\hline Comb' initial insertion length & $L$ & $350 \mu \mathrm{m}$ \\
Length of comb finger & $T_{t}$ & $700 \mu \mathrm{m}$ \\
Dielectric constant of electret film & $e p 1$ & 3.5 \\
Dielectric constant of air gap & $e p 2$ & 1.0 \\
Dielectric constant & $e p$ & $8.854 \times 10^{-12}$ \\
Mass & $m$ & $0.0015 \mathrm{~kg}(1.5 \mathrm{~g})$ \\
Height of comb finger & $H$ & $100 \mu \mathrm{m}$ \\
Electret depth in electret film & $R$ & $0.79 \mu \mathrm{m}$ \\
Thickness of electret film & $T$ & $0.8 \mu \mathrm{m}$ \\
Number of comb pairs & $N$ & 900 \\
Electret potential & $V_{e}$ & $-250 \mathrm{~V}$ \\
Air gap between comb fingers & $g$ & $14 \mu \mathrm{m}$ \\
\hline
\end{tabular}




\subsection{Design of SPICE module of electret-based MEMS energy harvester}

The subcircuit model for the electrostatic force and electrostatic induction current is implemented as an equivalent circuit that runs on the LTspice platform. The current source of LTspice is used as a multiphysics behavior model that can be programmed using the unitless physical variables in algebraic equations. The fundamental programming technique has been reported elsewhere. ${ }^{(33)}$ Figure 3(a) shows the circuit diagram of the electret actuator module unit based on the comb-electrode structure. When the displacement of a movable electrode

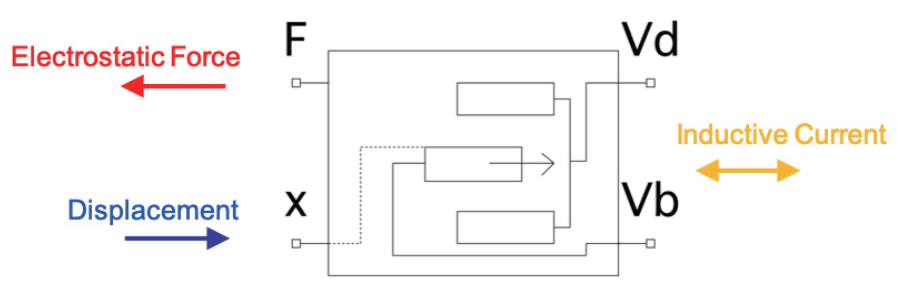

(a)

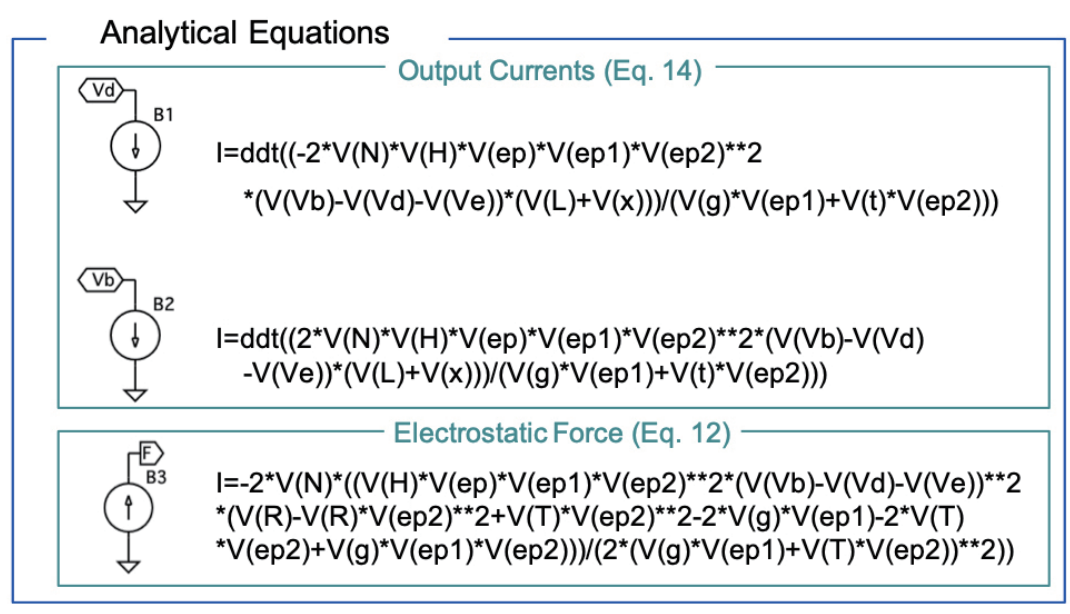

(b)

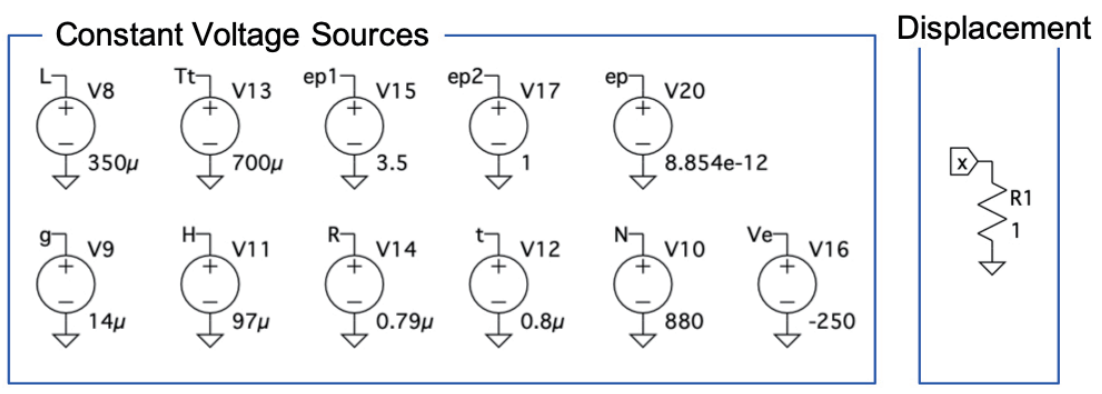

(c)

Fig. 3. (Color online) (a) LTspice equivalent circuit module for electret comb electrodes. (b) Analytical model implementation of electrostatic force and electrostatic induction current. (c) Internal parameters defined by constant voltage sources. 
is imported, the subcircuit model relays electrostatic force back to the model of a spring-mass system. At the same time, the inductive current obtained by the electron flows to an external circuit. Here, the equations of the electrostatic force [Eq. (12)] and the output current [Eq. (14)] are directly described for the nonlinear current source in the subcircuit model, as shown in Fig. 3(b). In this SPICE simulator, physical constants are defined by the constant-voltage sources within the module. The imported displacement parameter is terminated with a $1 \Omega$ resistor and is read out as a voltage for internal use, as shown in Fig. 3(c).

The circuit model of the vibrational energy harvester consists of two comb-electrode subcircuit models (left and right) and a velocity-damped resonant generator (VDRG) model as shown in Fig. 4; the design parameters and the initial conditions used are listed in Table 1. The two comb electrodes are placed symmetrically to cancel out the internal electrostatic forces. Figures 5(a) and 5(b) respectively show the circuit description for the suspension and the mass modules; the former reads in the displacements $\left(x_{1}, x_{2}\right)$ and the velocities $\left(v_{1}, v_{2}\right)$ measured at the two ends of the suspension and returns the restoring forces $\left(F_{m 1}, F_{m 2}\right)$ as

$$
F_{m 1}=-F_{m 2}=c \cdot\left(v_{2}-v_{1}\right)+k \cdot\left(x_{2}-x_{1}\right)
$$

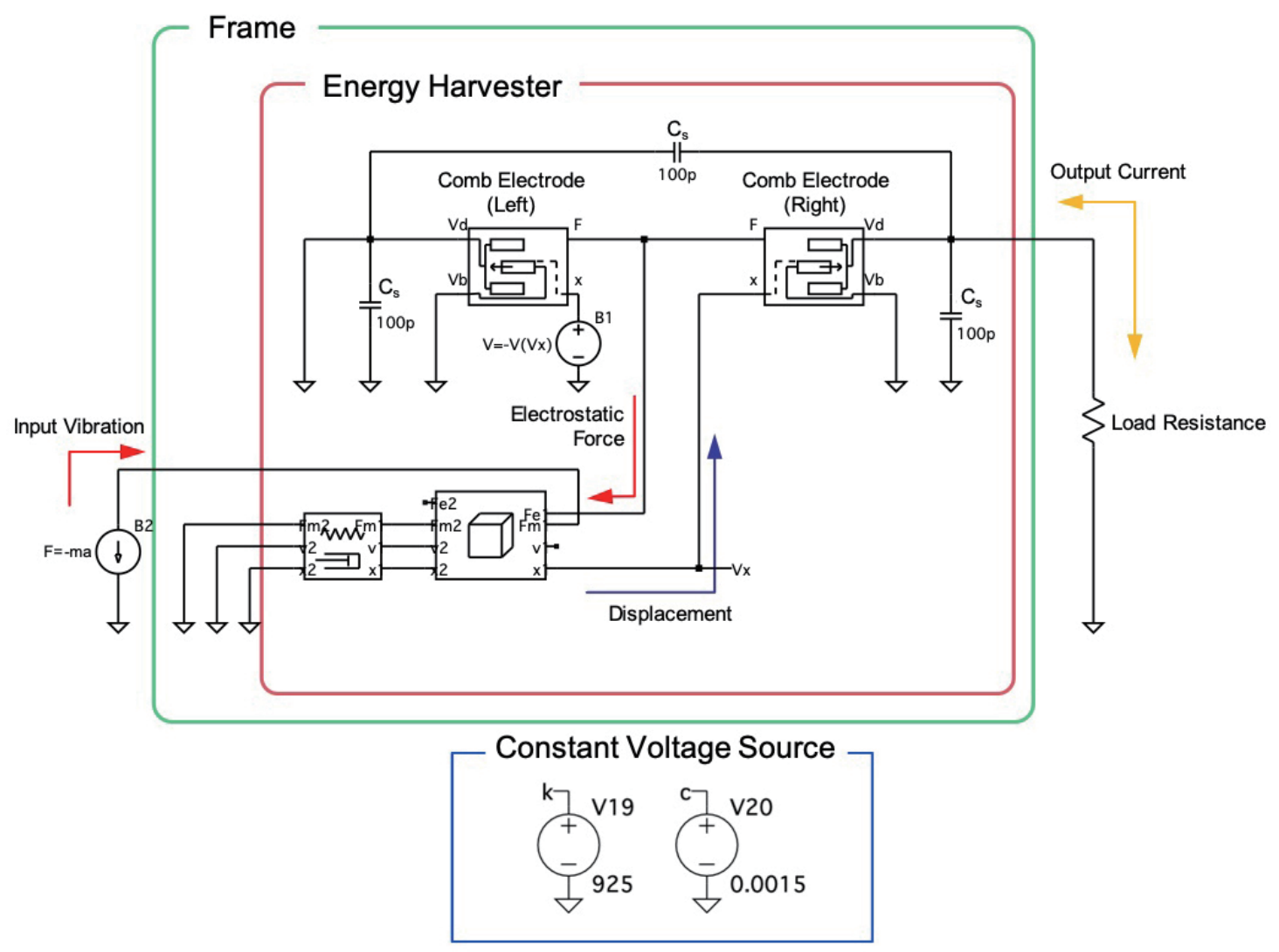

\section{Cs: Stray Capacitance}

Fig. 4. (Color online) LTspice equivalent circuit model of electret energy harvester with a pair of comb electrodes. 

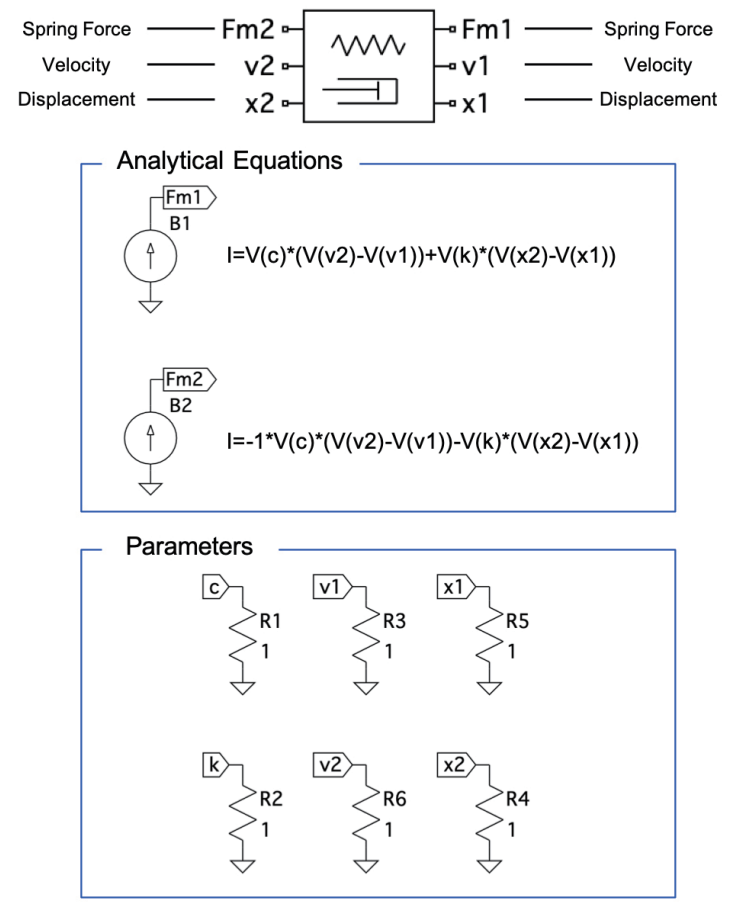

(a)
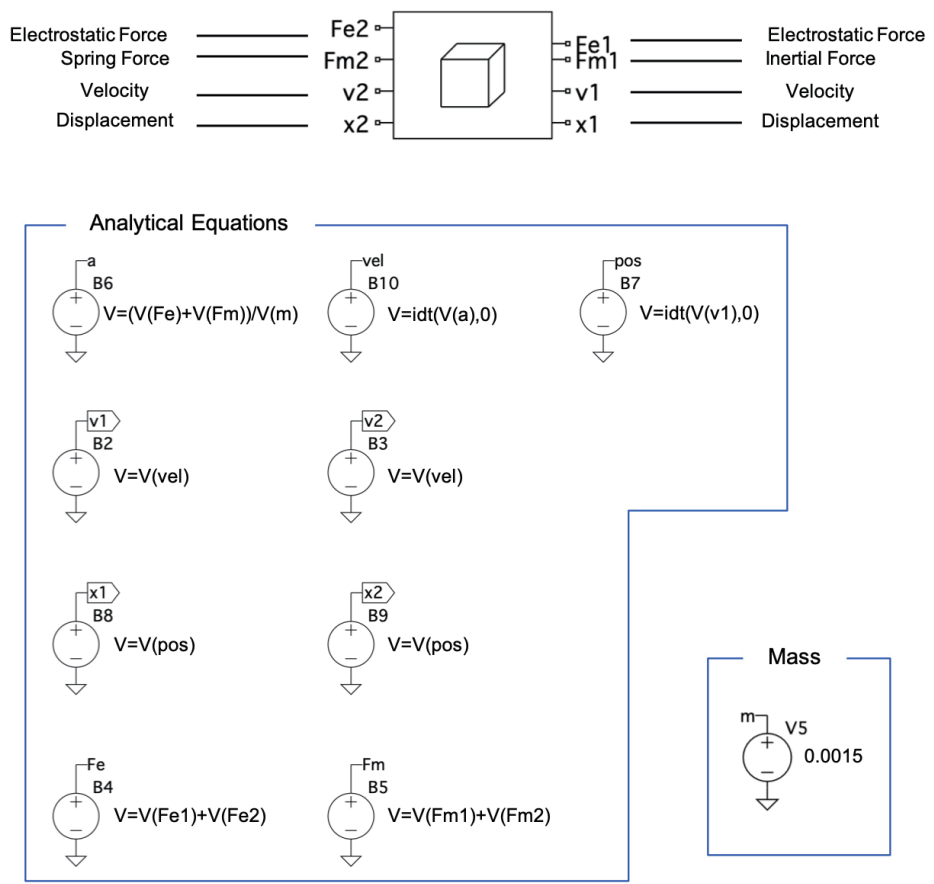

(b)

Fig. 5. (Color online) VDRG model for (a) the suspension and (b) the mass.

where $c$ and $k$ are the viscous damping coefficient and the spring constant, respectively. The mass module, on the other hand, reads in the electrostatic forces $\left(F_{e 1}, F_{e 2}\right)$ and the mechanical forces $\left(F_{m 1}, F_{m 2}\right)$ from both sides and returns the displacement and the velocity by solving the Newtonian equation of motion. The function idt in Fig. 5(b) is for temporal integration, such as $\operatorname{idt}(\mathrm{V}(\mathrm{a}), 0)$ for the integration of the acceleration a and $\operatorname{idt}(\mathrm{V}(\mathrm{v} 1))$ is for the integration of the velocity v1.

The external vibrations are defined as the inertial force $\left(F_{m 1}\right)$ acting on the movable mass $\mathrm{m}$, which is expressed using a nonlinear current source. It is also possible to express the incoming vibrations using time series data of acceleration measured from an actual vibration source such as a highway duct. The acceleration data could be read as a csv or a text file, and multiplied with the mass $\mathrm{m}$ to calculate the inertial force. This technique could be used for both sinusoidal and nonsinusoidal waves. The value for the connected stray capacitance $C_{S}$ is modeled from the electrical interconnection line area and buried oxide (BOX) thickness, which is calculated to be $100 \mathrm{pF}$.

\section{Verification of Applicability of Built Energy Harvester}

\subsection{Sinusoidal vibration}

To demonstrate the applicability of the previously described subcircuit model in the SPICE simulation, energy equivalence based on the input energy and the output energy is calculated, 
as shown in Fig. 6. The imported sinusoidal vibration is set to have an acceleration of $0.1 \mathrm{G}$ at the resonant frequency of $125 \mathrm{~Hz}$, and is defined using the nonlinear current source. Figure 6(a) shows the calculated amplitude, which gradually grows with resonance of the movable electrode. At this time, kinetic energy and strain energy in the subcircuit model are reciprocally transferred in accordance with the motion of the movable electrode, as shown in Fig. 6(b). Here, quantities of energy losses due to several factors in the subcircuit model are calculated and are indicated together in Fig. 6(c). It is commonly known that the factors that cause energy loss are of the following three types: mechanical loss, electrical loss, and energy stored in a spring-mass system. The total potential indicates the amount of energy stored in the spring-mass system, which is calculated by summing the kinetic energy and the elastic energy presented by Fig.

(a)

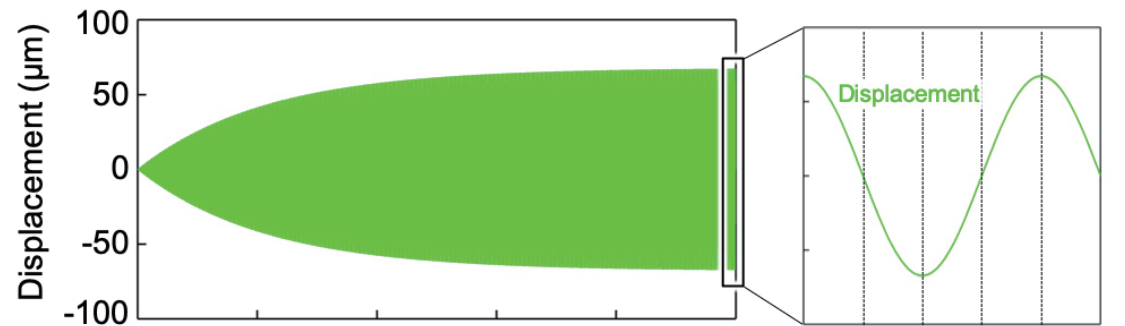

(b)

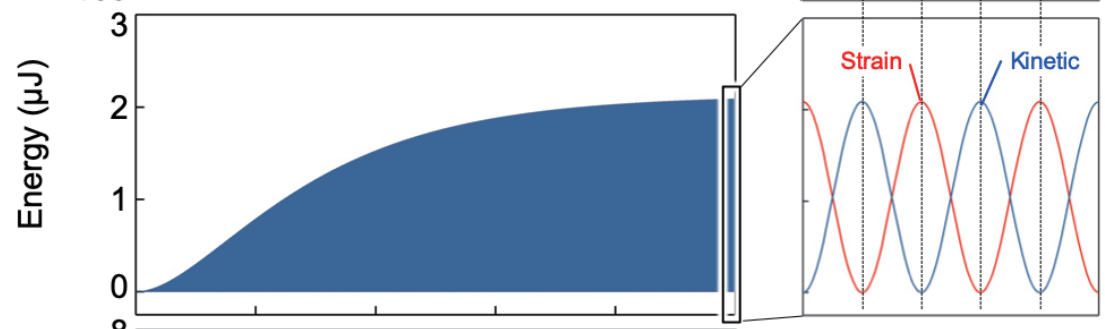

(c)

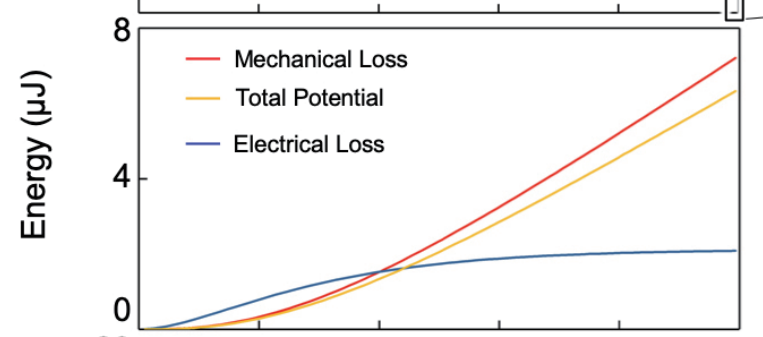

(d)

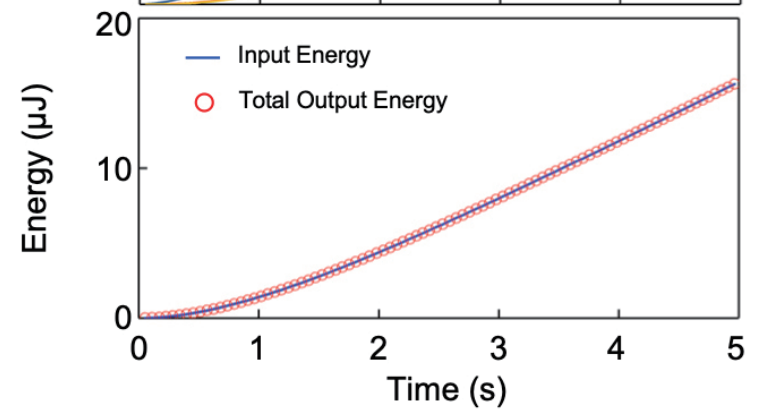

Fig. 6. (Color online) Simulation results of energy balance of MEMS vibrational energy harvester. (a) Displacement of movable electrode when shaken by $0.1 \mathrm{G}$ vibrations at $125 \mathrm{~Hz}$. (b) Potential energy stored in the suspension and kinetic energy of the mass. (c) Mechanical loss and electrical loss (output). (d) Input energy is equal to total output energy. 
6(b). Mechanical energy loss $V_{\text {Mechanical }}$ is calculated as an integrated value in which viscous resistance is time-integrated as

$$
V_{\text {Mechanical }}=\int c \cdot v e l^{2} d t
$$

where vel is the velocity of the movable electrode in Fig. 5(b).

In the same manner, electrical loss $V_{\text {Electrical }}$ is also calculated as a time-integrated value of an electrostatic force as

$$
V_{\text {Electrical }}=\int F_{e 1} \cdot \text { vel } d t \text {. }
$$

As a result, total output energy can be plotted as the total amount of energy consumed by the above-described three losses, as shown in Fig. 6(d). Moreover, the time-integrated workload as the input energy of the spring-mass system is also plotted together and is compared with the total output energy in the same figure. As can be seen from Fig. 6(d), the two curves indicating input and output energies are in complete agreement; therefore, it is evident from the calculated results that the energy balance of the subcircuit model is completely satisfied. Thus, the validity of the subcircuit models has been quantitatively verified.

To verify the applicability of the subcircuit model operated under the condition of receiving sinusoidal vibration, calculated values of the power generation performances obtained from the input sinusoidal vibration are quantitatively compared with the experimental values measured under the same condition. The electrical circuit used to measure the short-circuit current of the developed energy harvester ${ }^{(31)}$ is shown in Fig. 7(a). We used a current-voltage converter (Hamamatsu, C7319) with a large input impedance to isolate the measurement from the input impedance of the oscilloscope. The fixed electrode on the right was directly grounded, while the one on the left was connected to the virtual ground point of the operational amplifier. The experimentally observed short-circuit current waveform for the device operated with the sinusoidal vibration of $0.01 \mathrm{G}$ acceleration at $125 \mathrm{~Hz}$ is shown by the dots in Fig. 7(b), along with the calculated waveform indicated by the solid line. As can be seen in Fig. 7(b), the experimental current waveform is in good agreement with the calculated one.

The short-circuit current as a function of the input acceleration is calculated and quantitively compared with the experimental value to verify how well the relationship between output performance and input vibrational energy can be reproduced. Figure 8 indicates the shortcircuit current obtained when the movable electrodes oscillate within the stroke limit at resonance. The experimental value is represented by the dots and the calculated value is the solid curve. Here, the input acceleration is set to handle the maximum stroke $( \pm 350 \mu \mathrm{m})$ of the movable electrode. It is clear that short-circuit current is proportional to input acceleration since both functions are proportional to velocity. ${ }^{(31-34)}$ As shown in Fig. 8, both plotted currents are proportional to input acceleration. The developed device reached the maximum stroke at $0.020 \mathrm{G}$, while the modeled device in SPICE reached it at $0.022 \mathrm{G}$. Also, the obtained maximum shortcircuit current under the same condition was $5.0 \mu \mathrm{A}$ in the experiment and $5.2 \mu \mathrm{A}$ in the 


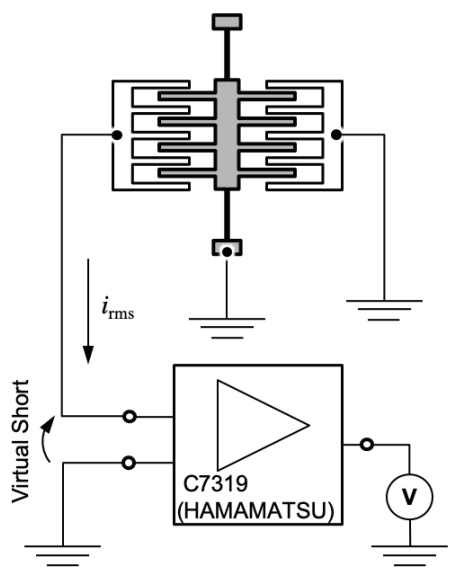

(a)

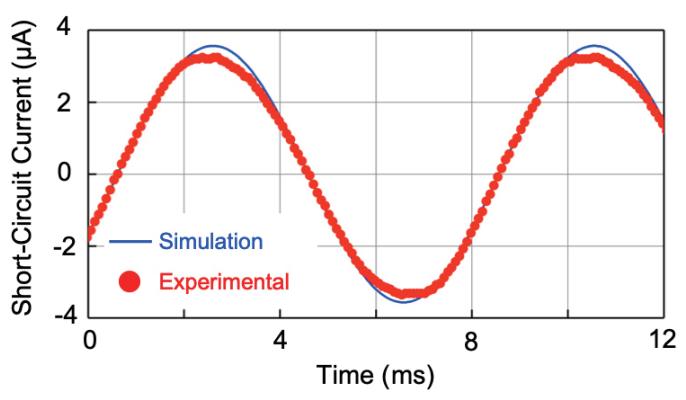

(b)

Fig. 7. (Color online) (a) Circuit for measuring the short-circuit current. (b) Simulated and experimental shortcircuit current excited by $0.01 \mathrm{G}$ acceleration at $125 \mathrm{~Hz}$.

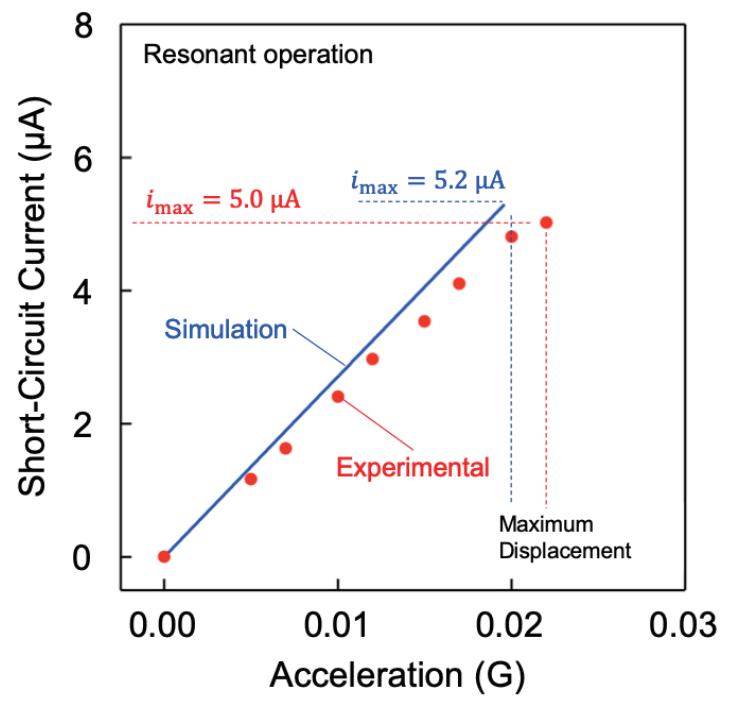

Fig. 8. (Color online) Simulated and experimental short-circuit currents as a function of acceleration at resonance.

simulation. Thus, the experimental values are in good agreement with the calculated values even when oscillated at maximum displacement.

For another verification, a comparison between the input and output energies is performed, under the condition that generated power is electrically consumed by the external load applied for the verification. Figure 9(a) shows the electrical circuit used to measure the output power for the device connected to the optimal load and operated at its resonant frequency $(125 \mathrm{~Hz})$. Here, the electrical power consumed as the external electrical loss is estimated from the output current flowing through the load resistance of $7 \mathrm{M} \Omega$. Hence, the output power as a function of the input acceleration is experimentally obtained and shown in Fig. 9(b). The output power 


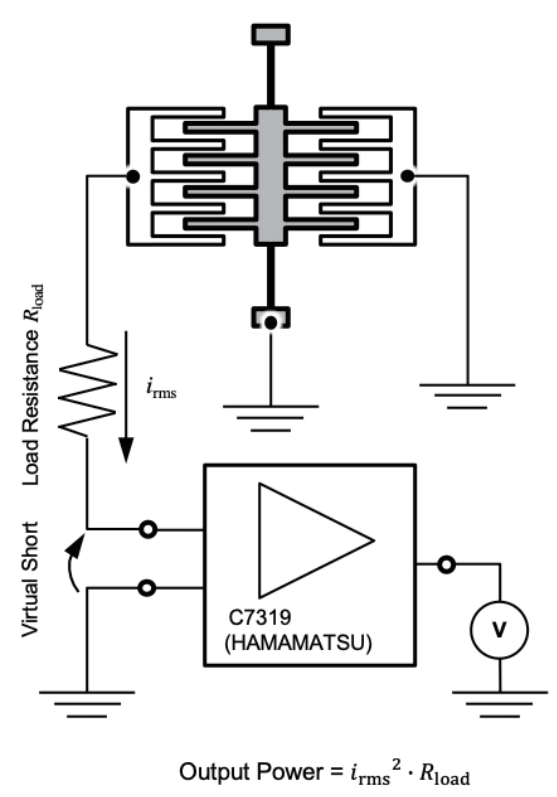

(a)

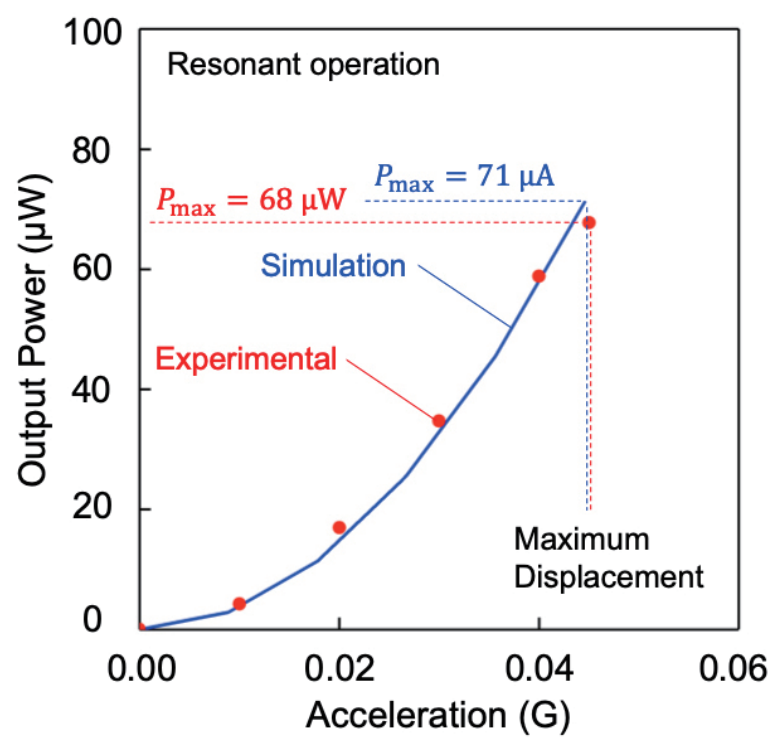

(b)

Fig. 9. (Color online) (a) Electrical circuit for measuring the output voltage across the load resistance. (b) Simulated and experimental output voltages at resonance.

calculated using the subcircuit model under the same conditions as the actual device is also shown by the solid curve. When the external vibration frequency matches the harvester's eigenfrequency $\omega$, then the output power is generally described as ${ }^{(35)}$

$$
P_{\text {out }}=\frac{1}{2} m \omega^{3} Q y^{2} E_{H}=\frac{1}{2} m \omega^{3} Q\left(\frac{G \times 9.8}{\omega^{2}}\right)^{2} E_{H},
$$

where $E_{H}$ indicates the harvester effectiveness. Here, as is clear from this equation, the power is proportional to the square of the acceleration $G$. As seen in Fig. 9(b), this relation was clearly shown by both curves of output power. When the device was excited at its resonance such that the movable electrode oscillated at its limit of $\pm 350 \mu \mathrm{m}$, the maximum output power was calculated to be $71 \mu \mathrm{W}$ at $0.044 \mathrm{G}$ using the simulation module. On the other hand, the output power of the actual device reached $68 \mu \mathrm{W}$ at $0.045 \mathrm{G}$. Thus, the experimental values are in good agreement with the calculated ones. When we take a close look at the horizontal axis, the acceleration necessary for the maximum stroke increases compared with that under the no-load condition $(0.020 \mathrm{G})$. This result can be explained by the kinetic energy stored in the springmass system to move the electrode being electrically consumed by an energy conversion system with an electret. Consequently, in this subcircuit model, degradation of the quality factor in accordance with the electrical loss by the electret was also accurately reproduced in the simulation results. 
The comparison of the simulation and experimental results revealed that the assembled SPICE simulator reproduces the relationship between the amplitude of the movable electrode and the change rate of inductive charges. An excellent agreement was found in all cases even when input acceleration was changed. Thus, the subcircuit model and its applicability in cases of sinusoidal vibration were validated.

\subsection{Nonsinusoidal vibration}

In this paper, the output-generating performance of a developed device under nonsinusoidal vibration is also experimentally observed and quantitatively compared with the performance calculated under the same conditions using SPICE. To verify the output voltage in the case of nonsinusoidal vibration, the typical environmental vibration was measured using an accelerometer (Emic, P51CAC57) at a highway duct. At the same time, the output voltage of the developed harvester placed at the same spot was observed.

Figure 10(a) shows the time-series pattern of acceleration on the measured ambient environmental vibration. Figure 10(b) shows the results of wavelet analysis of the acceleration. Here, the operating direction of the energy harvester corresponds to the measured axis of the accelerometer. The energy harvester is modified with additional mass to be $2.8 \mathrm{~g}$ with an electret potential of $-200 \mathrm{~V}$. Thus, the resonant frequency is down-shifted to $91 \mathrm{~Hz}$ owing to the increase in the additional mass, and the estimated mechanical damping is 0.0073 . For this measurement setup, the fixed electrode on the left is directly connected to the input terminal in the oscilloscope, and the output voltage is observed across the $1 \mathrm{M} \Omega$ resistance.

Figure 10(c) shows the collected pattern of the output voltage that is synchronized with the time of acceleration in Fig. 10(a). By comparing Figs. 10(a) and 10(c), we see that the graph pattern of the observed output voltage does not resemble the pattern of the time-series data of acceleration. Since the energy harvester is responsive to the input vibrations corresponding to its resonance only, the two graph patterns will not necessarily match. The timing of the wavelet peak in Fig. 10(b) naturally matches the timing of the surge of the acceleration in Fig. 10(a). On the other hand, the timing of the measured peak voltage in Fig. 10(c) does not necessarily match those of the acceleration surge in Fig. 10(a) but to the timing of the appearance of the frequency component near the mechanical resonance of the harvester $(91 \mathrm{~Hz})$. In other words, the waveform of the harvester voltage differs from that of the acceleration because the characteristics of the gained voltage have been filtered and enhanced by the mechanical resonance of the harvester.

Figure 10(d) shows the output voltage estimated using the subcircuit model input with the measured time-series data of acceleration. The waveforms of the measurement in Fig. 10(c) and the simulation in Fig. 10(d) do not give a perfect match. In both patterns of the time series, however, the timing of the highest generated peak was $5.6 \mathrm{~s}$. At the same time, the experimental and simulated amplitudes were obtained to be 0.80 and $0.63 \mathrm{~V}$, respectively, in the almost similar range. Furthermore, other peaks of the collected output voltages were in good agreement with the calculated one. The results indicate that the developed simulation model can reproduce the harvester behavior at a frequency near the mechanical resonance. 
(a)

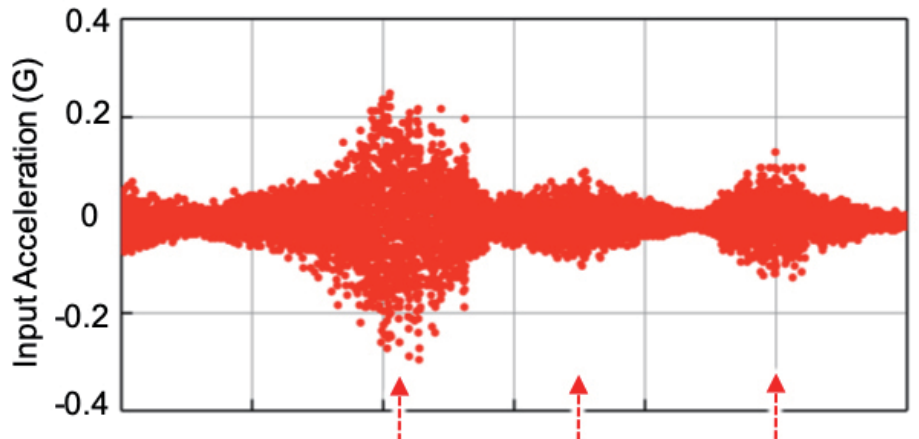

(b)

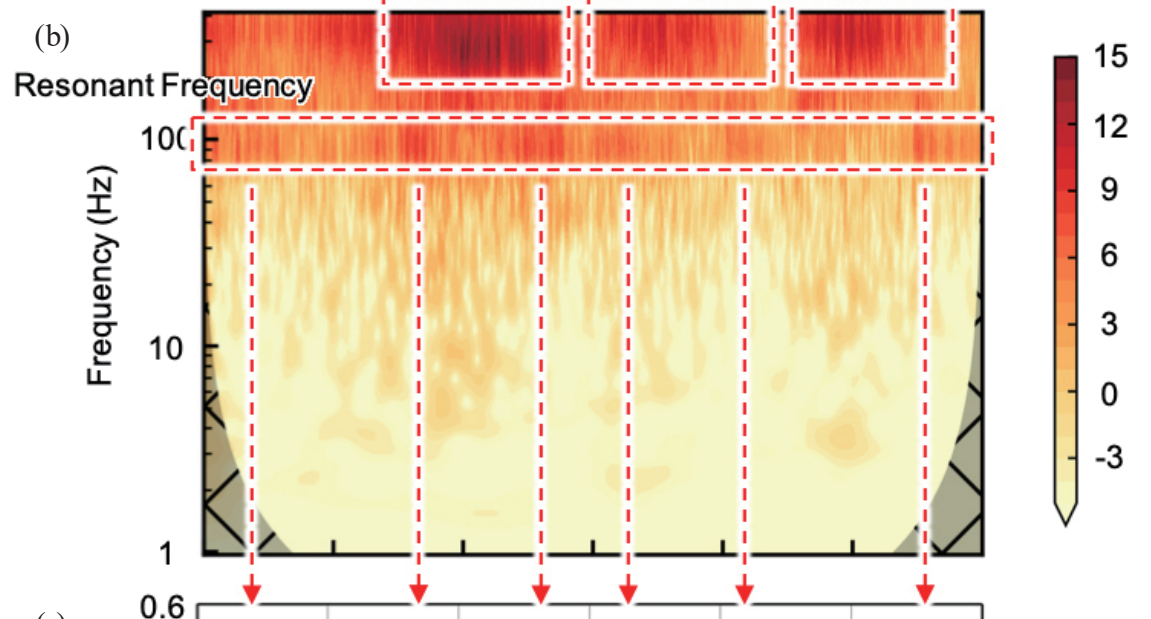

(c)

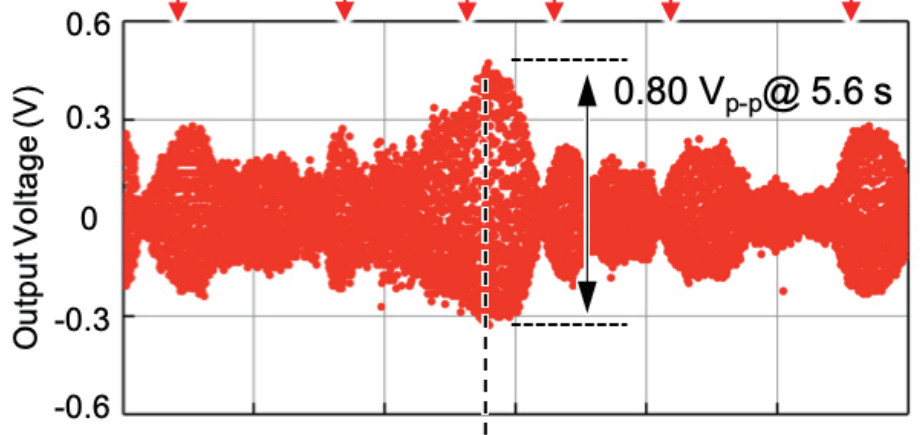

(d)

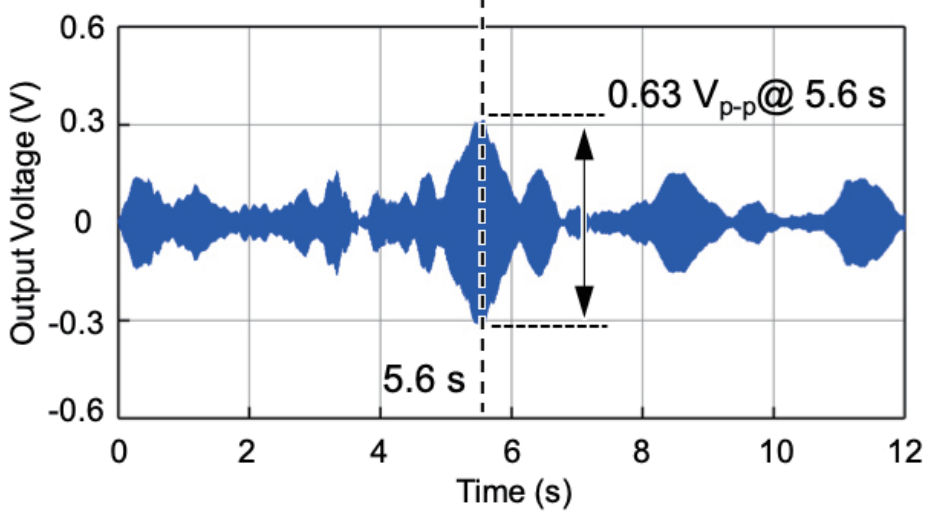

Fig. 10. (Color online) (a) Acceleration signal measured on an actual vibration source (highway duct) and (b) wavelet analysis of the acceleration. (c) Output voltage of MEMS energy harvester measured simultaneously on site. (d) Simulation result of the equivalent circuit model excited by the same vibrations. 
However, the calculated voltage pattern is not completely the same as the experimentally observed voltage pattern, as shown in Figs. 10(c) and 10(d). Figure 11 shows the Fouriertransformed time-series data of the experimentally measured acceleration. The measured vibration is mostly distributed in the frequency range below $400 \mathrm{~Hz}$. On the other hand, Fig. 12 shows the experimental frequency response spectrum from the actual device that defines the resonant frequency to be in the range of $90.5-91.5 \mathrm{~Hz}$.

To verify the responding frequency range of the energy harvester, the wavelets of the timeseries data of the observed and calculated output voltages were transformed, as shown in Figs. 13(a) and 13(b), respectively. It was expected that the wavelet of the actual device would act as shown in Fig. 13(b), but only at resonant frequency. However, the collected data was analyzed and the results are shown in Fig. 13(a). There is a slight response around the resonant frequency with a tendency of increase toward the high frequency.

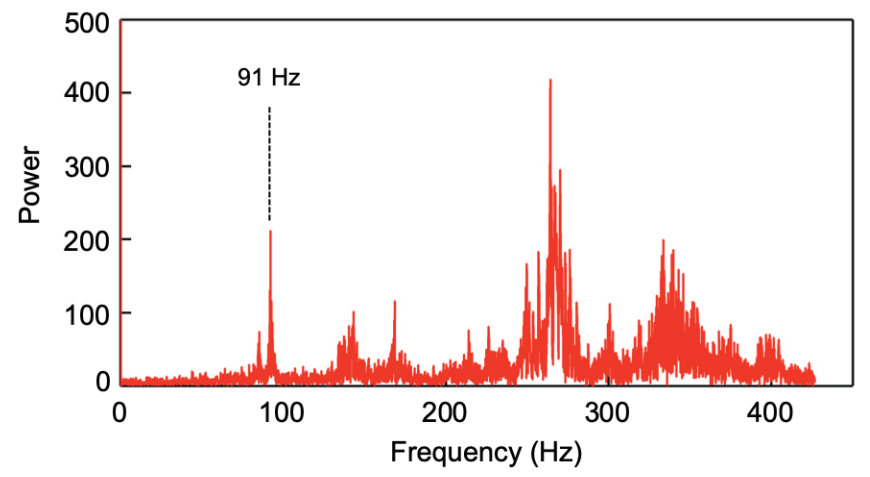

Fig. 11. (Color online) Results of FFT analysis of excitation vibrations.

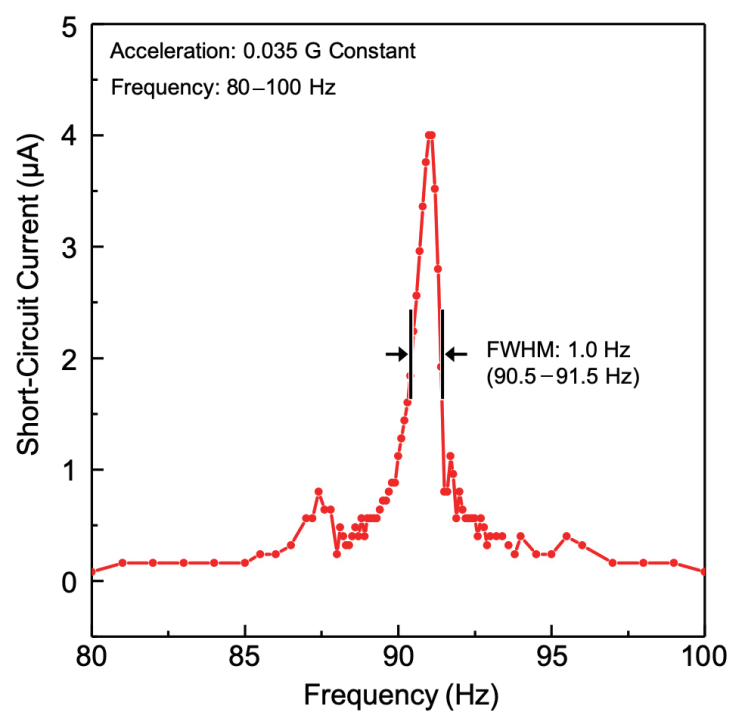

Fig. 12. (Color online) Frequency spectrum of short-circuit current of the energy harvester used for the on-site measurement. 


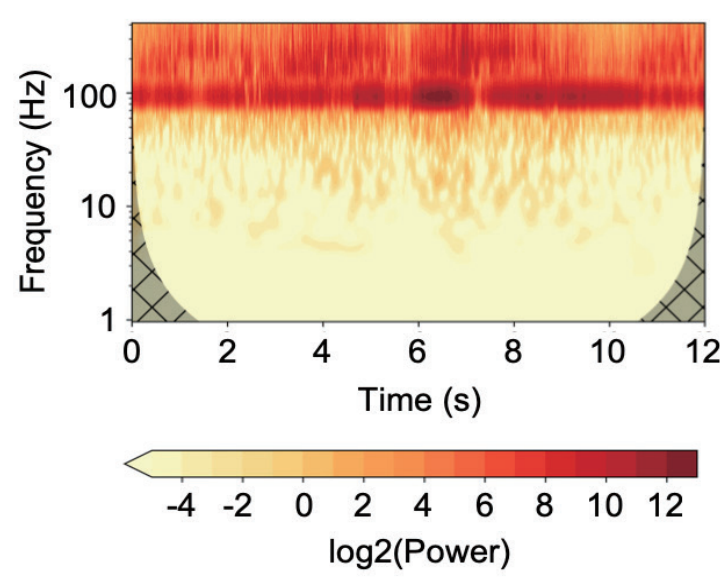

(a)

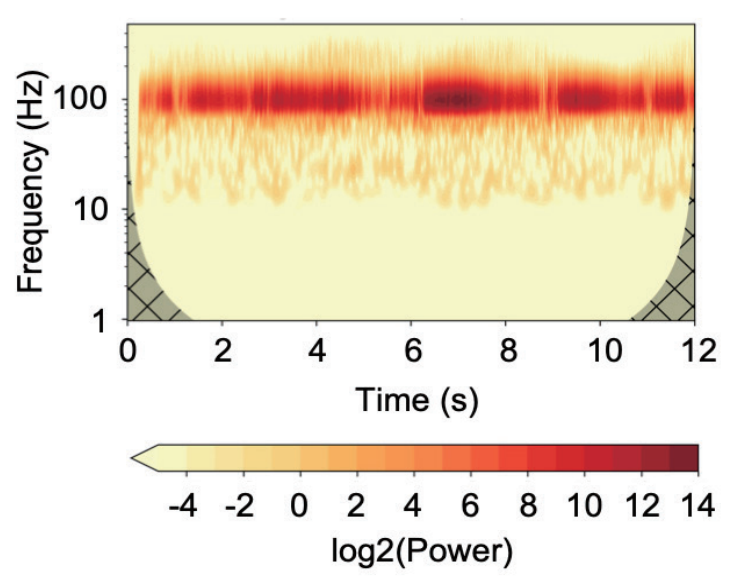

(b)

Fig. 13. (Color online) Wavelet analysis results for (a) experimentally obtained output voltage and (b) simulated output voltage.

The possible reason for this discrepancy is that the analytical model only responded to input vibrations corresponding to its resonance; however, the real device also responded to input vibrations other than those of its resonance. The actual device responded to the vibrations in various directions. Moreover, because the assembled model in SPICE only defines the vibration in the axis corresponding to the operation direction of the vibrational energy harvester, it cannot respond to other axes. Thus, there is a slight difference between the two patterns of output voltage. This effect could be included in the simulation by expanding the one-dimensional model into two or three dimensions, which is to be performed in future work.

\section{Conclusions}

Analytical models for the vibrational energy harvester based on the comb structures coated with the permanent charge or electret were represented using a SPICE simulator. To verify the applicability of the subcircuit model for various vibrations, several sinusoidal and nonsinusoidal vibrations were input as nonlinear current sources emulating the inertial force, and each outputgenerating performance was simulated. The simulation results and experimental results obtained from the actual device under the same conditions were compared. For sinusoidal vibration, excellent agreement was found in all cases even when the input acceleration was changed. Furthermore, peaks of the collected output voltages were in good agreement with the calculated one even when the external vibration was nonsinusoidal. Therefore, the applicability of the model to cases of sinusoidal and nonsinusoidal vibrations was confirmed. However, the calculated voltage patterns were not completely the same as the experimentally observed voltage patterns under the condition of inputting nonsinusoidal vibration. The assembled model still did not respond well to multiple axes because it only defines vibration in the axis corresponding to the operation direction of the vibrational energy harvester. In future work, the assembled subcircuit model corresponding to multiple axes must also be implemented in the SPICE module. 


\section{Acknowledgments}

This work was supported by JST CREST Grant Number JPMJCR15Q4. This work was also supported by JSPS Grant-in-Aid for Scientific Research (B), Grant Numbers 18H01490 and 19K15038. We also thank Prof. Hidehiko Sekiya of Tokyo City University for providing the data of nonsinusoidal vibrations.

\section{References}

1 L. Atzori, A. Lera, and G. Morabito: Comput. Networks 54 (2010) 2787.

2 S. Roundy, P. K. Wright, and J. Rabaey: Comput. Commun. 26 (2003) 1131.

3 H. Liu, C. J. Tay, C. Quan, T. Kobayashi, and C. Lee: J. Microelectromech. Syst. 20 (2011) 1131.

4 S. Priya: J. Electroceram 19 (2007) 165.

5 J. A. Paradiso and T. Starner: IEEE Pervasive Comput. 4 (2005) 18.

6 N. S. Hudak and G. G. Amatucci: J. Appl. Phys. 103 (2008) 101301.

7 S. Kim and Y. Suzuki: Proc. 2016 IEEE SENSORS. https://doi.org/10.1109/ICSENS.2016.7808819

8 Q. Fu and Y. Suzuki: Proc. 2015 18th Int. Conf. Solid-State Sensors, Actuators and Microsystems (TRANSDUCERS2015) 1925.

9 Q. Fu and Y. Suzuki: J. Phys.: Conference Series 476 (2013) 012112.

10 K. Tao, S. W. Lye, J. Miao, L. Tang, and X. Hu: J. Micromech. Microeng. 25 (2015) 104014.

11 Y. Zhang, T. Wang, A. Luo, Y. Hu, X. Li, and F. Wang: Appl. Energy 212 (2018) 362.

12 H. Asanuma, M. Hara, H. Oguchi, and H. Kuwano: AIP Adv. 6 (2016) 075206.

13 F. Wang and O. Hansen: Sens. Actuators, A 211 (2014) 131

14 P. Basset, D. Galayko, F. Cottone, R. Guillemet, E. Blokhina, F. Marty, and T. Bourouina: J. Micromech. Microeng. 24 (2014) 035001.

15 Y. Chiu and Y. -C. Lee: J. Micromech. Microeng. 23 (2013) 015012.

16 N. Sato, K. Ono, T. Shimamura, K. Kuwabara, M. Ugajin, and Y. Sato: J. Microelectromech. Syst. 21 (2012) pp. $1218-1228$.

17 C. P. Le and E. Halvorsen: J. Micromech. Microeng. 22 (2012) 074013.

18 K. Tao, J. Miao, S. W. Lye, and X. Hu: Sens. Actuators, A 228 (2015) 95.

19 A. Crovetto, F. Wang, and O. Hansen: J. Micromech. Microeng. 23 (2013) 114010.

20 B. Yang, C. Lee, R. K. Kotlanka, J. Xie, and S. P. Lim: J. Micromech. Microeng. 20 (2010) 065017.

21 T. Masaki, K. Sakurai, T. Yokoyama, M. Ikuta, H. Sameshima, M. Doi, T. Seki, and M. Oba: J. Micromech. Microeng. 21 (2011) 104004.

22 Y. Suzuki, D. Miki, M. Edamoto, and M. Honzumi: J. Micromech. Microeng. 20 (2010) 104002.

23 H. Koga, H. Mitsuya, H. Honma, H. Fujita, H. Toshiyoshi, and G. Hashiguchi: MDPI Micromach. 8 (2017) 293.

24 B. D. Truong, C. P. Le, and E. Halvorsen: Int. J. Electron. Commun. 107 (2019) 125.

25 E. R. Westby and E. Halvorsen: IEEE/ASME Trans. Mechatronics 17 (2012) 5.

26 M. S. Salem, A. A. Zekry, and H. F. Ragai: Proc. 2009 26th National Radio Science Conf. (NRSC2009) 1.

27 M. Farnswortha and A. Tiwaria: Procedia CIRP 38 (2015) 271.

28 K. Minami, T. Fujita, K. Sonoda, N. Miwatani, K. Kanda, and K. Maenaka: J. Phys.: Conf. Series 557 (2014) 012040 .

29 K. Minami, T. Fujita, T. Onishi, K. Sonoda, N. Miwatani, K. Kanda, and K. Maenaka: IEEJ Trans. Sens. Micromach. 135 (2015) 116.

30 Y. Tohyama, H. Honma, B. Durand, T. Sugiyama, G. Hashiguchi, and H. Toshiyoshi: Sens. Mater. 31 (2019) 2779.

31 H. Honma, H. Mitsuya, G. Hashiguchi, H. Fujita, and H. Toshiyoshi: J. Micromech. Microeng. 28 (2018) 0645005-1-064005-13.

32 G. Hashiguchi, D. Nakasone, T. Sugiyama, M. Ataka, and H. Toshiyoshi: AIP Adv. 6 (2016) 035004.

33 K. Misawa, T. Sugiyama, G. Hashiguchi, and H. Toshiyoshi: IEEJ Trans. Sens. Micromech. 134 (2014) 357.

34 H. Honma, Y. Tohyma, H. Mitsuya, G. Hashiguchi, H. Fujita, and H. Toshiyoshi, J. Micromech. Microeng. 29 (2019) 084002-1-084002-9.

35 H. Toshiyoshi, S. Ju, H. Honma, C.-H. Ji, and H. Fujita: Sci. Technol. Adv. Mater. 20 (2019) 125. 